definite eoliths in the sub-Crag detritus-bed-where no Chellean implements occur. In recent yearsin two investigations carried out by me-I have found implements of eolithic form in Acheulean, and in Late Moustierian occupation levels, and such specimens may occur in even later cultures. But there is no doubt in my mind that the most ancient eoliths, by reason of $(a)$ their presence in the sub-Crag detritus-bed, $(b)$ their archaic forms and workmanship, and $(c)$ the fact that they represent the ancestral types from which the normal sub-Crag implements were derived, must be regarded as the oldest implements in flint known to science, and as definitely pre-dating the earliest Chellean-palæolithic-hand-axes.

One House, Ipswich. J. REID MOIR.

\section{Formation of Mammato-Gloud.}

IN view of the recent letters in NATURE on the cause of mammato-clouds, some observations on the conditions accompanying them may be of interest. The only case I can find when an aeroplane observation was made in mammato-cloud was over Berck (N.E. France) on the evening of July $17, x 918$, at the height of II, OOO feet, at the base of a large mass of " anvil " cloud which had been carried by a strong upper current in advance of a line of thunderstorms, and extended up to the cirrus level. In this case the air was very turbulent, there was strong evidence of a downward current, and the lapse-rate of temperature was intermediate between the dry and saturated adiabatic rates. The cloud had the true bulging spherical structure, but the outline was not sharp, so that it was not a very good example. This was probably due partly to evaporation, partly to snowflakes melting into rain-drops. As a general rule " anvil" clouds consist almost entirely of snowflakes.

Mammato-clouds also developed on the flank of a thunderstorm on May 22, and a very striking example occurred in rear of a storm on July 20,1918 . Upper air temperatures and humidities observed before and after these storms have been published by the Meteorological Office (Professional Notes, No. 8), but it is observations in and below the clouds themselves that are required.

The mammato-form normally develops under a lateral extension of cumulo-nimbus, at a greater height than their base. It is true that the cloud is occasionally quite low, but in these cases the base of the cumulo-nimbus may originally have been still lower. This may explain the great apparent density at the base of the best examples of mammato-cloud. In an ordinary cumulus or turbulent strato-cumulus cloud, the amount of water, ice, or rime (the two latter from supercooled drops) which is deposited on an aeroplane is usually greater in the middle of the cloud than it is near the base. The height of thunderclouds, measured from the base to the top, is rarely less than 10,000 feet, and is usually much greater. When mammato-clouds develop from other forms, such as heavy strato-cumulus or alto-stratus, the thickness of the clouds does not appear less than four or five thousand feet.

There is a small-grained variety of mammatocloud, illustrated by Fig. $2 \mathrm{r}$ of the recent French official publication "Les Systèmes nuageux," and a similar structure is occasionally seen on the upper surface of a cloud-sheet, though on occasions different from those of its appearance underneath. The chief characteristic is that the normal rippled appearance is replaced by a spherical structure. The best examples are seen with a lapse-rate of temperature close to the saturated adiabatic within and above the clouds. If this rate is exceeded the sheet grows up irregularly (the "castellatus" form), while if there is an inversion above the clouds the upper surface is comparatively level, unless disturbed by large cumulus clouds below.

South Farnborough, Hants, March 3 .

\section{Elizabeth Barrett Browning and Scientific} Achievement.

PERhaps few people now read the poetry of Elizabeth Barrett Browning, but some days ago, in an idle mood, I took down one of the volumes of her collected works and chanced to open upon "Lady Geraldine's Courtship."

I feel sure that readers of NATURE will be as interested as I was to find the following warning and protest against the intellectual vanity and material tendency of the thought of the time, and also to come upon what has proved a remarkable forecast of the later achievements of science. It must be remembered that these verses were written in the forties or fifties of the nineteenth century; their author died in $186 \mathrm{I}$, and the first collected edition of her poems was dedicated to her father in 1844 .

How little did the writer dream that what to her were but fantastic and illusive phantoms would, within a comparatively few years, have taken shape and become the commonplaces of the day. These are the extracts :

We are Gods by our own reck ning and may well shut up the temples...

For we throw out acclamations of self-thanking, selfadmiring

Little thinking if we work our Souls as nobly as our iron Or if angels will commend us at the goal of pilgrimage.

Why, what is this patient entrance into nature's deep resources

But the child's most gradual learning to walk upright without bane?

If we trod the deeps of ocean, if we struck the stars in rising, If we wrapped the globe intensely with one hot electric breath, 'Twere but power within our tether, no new spirit-power comprising,

And in life we were not greater men, nor bolder men in death.

Letterawe, Loch Awe, February 28.

\section{Prof. J. Symington.}

IN the obituary of Prof. Symington that appeared in NATURE of March 22, p. 432, no mention is made of his most important contribution to science. I refer to his discovery, in 1892 , that the so-called corpus callosum in the brains of monotremes and marsupials is really a hippocampal commissure. In $x 835$ Owen had directed attention to the fact that the corpus callosum was absent in these animals : but thirty years later Flower denied Owen's claims, and until Symington demonstrated the correctness of Owen's work and his interpretation of it, Flower's conclusions had been generally accepted, even by a series of distinguished anatomists who had themselves examined the structure of the marsupial brain.

In the early nineties of last century, three investigators had independently discovered that after all Owen was right; but the credit belongs to Symington of having been the first to record the fact that completely revolutionised our ideas of the morphology of the cerebral hemisphere.

G. Elliot Smith.

$$
\text { NO. } 2839 \text {, VOL. II } 3]
$$

